\title{
Convergence Process in the European Region - Cluster Analysis
}

\author{
Stanislav Burian • Josef Brčák
}

Published online: 20 August 2014

(C) International Atlantic Economic Society 2014

JEL E00

The primary aim of our research was to assess the character of the convergence process in member countries of the European Union during the period 2002-2012. For this purpose, we applied cluster analysis, a multivariate statistical technique. The results of the cluster analysis allowed us to classify countries into several groups with similar features. In this context, we compared cluster analysis results for single years from period 2002-2012. This comparison allows us to measure whether certain changes exist in defined clusters because changes in particular clusters can be interpreted as divergence or convergence tendencies. We analyzed whether the group (which represents the Eurozone core) was defined more broadly during the analyzed period or not. A more broadly defined core suggests that certain countries converge to the Eurozone core. Data for the convergence criteria for individual countries were obtained from the Eurostat, OECD, and IMF databases, or from the statistical offices of the countries under analysis.

An important contribution to this research area was written by Artis and Zhan (International Journal of Finance and Economics, 1997), which classified a sample of 18 developed countries around the globe into five groups. Three clusters were identified in the European context: core (France, the Netherlands, Belgium and Austria), northern periphery (Denmark, Ireland, Sweden, Norway, Finland and the UK) and southern periphery (Italy, Spain, Portugal and Greece). Cluster analysis was also used to explore the convergence process by Krcilkova (Agrarian Perspectives XV, 2006), who clustered the countries in the European Union using growth in the gross domestic product (GDP), the inflation rate derived from the GDP deflator, the unemployment level, real interest rates and the public budget deficit versus GDP as convergence criteria. In her conclusions, she provides evidence for significant convergence in the economies

\footnotetext{
S. Burian $(\bowtie) \cdot J$. Brčák

Faculty of Economics and Management, Department of Economic Theories, Czech University of Life Sciences, Prague, Czech Republic

e-mail: burians@pef.czu.cz

J. Brčák

e-mail: brcak@pef.czu.cz
} 
of the member countries during the period analyzed (1997-2005). Further publications exploring the convergence of countries located in the European economic area via cluster analysis include Boreiko (International Journal of Finance and Econometrics, 2003), who used a fuzzy approach to cluster analysis to assess the potential entry of countries located in Central and Eastern Europe to the Eurozone, Tsangarides and Qureshi (IMF working paper, 2006), who used a similar methodology to evaluate the sustainability of a fixed currency regime in Western Africa, and Crowley (Bank of Finland working paper, 2008), who used correlation indicators as features for cluster analysis (applied to 32 countries).

We conducted 11 cluster analyses applied to 25 objects (countries) and 6 variables (optimum currency area [OCA] criteria), one analysis for each year for the period 2002 through 2012. Twenty-five member states of the OECD (cluster analysis objects) were chosen due to the aims of this paper and data availability. Variables were defined with respect to OCA theory. More specifically, we used openness of countries, long-term interest rates, GDP in purchasing power parity, position in the business cycle, flexibility in the labor market, and price level.

According to assumptions, we categorized chosen countries into 4 groups: "outside group", "core of the EU", advanced "old periphery" of the EU and "new periphery" including transformed countries. We found that transitive economies approached the EU core in their chosen economic characteristics during the period. In 2002, transitive countries created one specific cluster. According to assumptions about the convergence process, countries situated in Central Europe gradually should become a part of the "core cluster". Alternatively, at least the distance between the "core croup" and the "new periphery" should be minor.

Next, the distance between the "new periphery" and the "core group" was lower in 2012 (55\% relatively expressed) than in 2002 (100\%). Several countries of the EU have indicators similar to "outside" economies rather than the EU. The United Kingdom was involved in the "outside group" for every year of the period 2002-2012 except 2007. After the crisis (from 2009), Finland belonged to the "outside cluster".

Generally, it is possible to claim that there is no permanent significant convergence process in the EU. In the case of more intensive convergence, the distance among clusters should be declining over time. However, the cluster analyses' results did not define decreasing tendencies in cluster distances among European countries because these distances were fluctuating during the analyzed period. 